\title{
Almanac 2012 Adult Cardiac Surgery: The National Society Journals Present Selected Research That Has Driven Recent Advances In Clinical Cardiology
}

\section{Ben Bridgewater}

Abstract

\begin{abstract}
This review covers the important publications in adult cardiac surgery in the last few years, including the current evidence base for surgical revascularisation and the use of off-pump surgery, bilateral internal mammary arteries and endoscopic vein harvesting. The changes in conventional aortic valve surgery are described alongside the outcomes of clinical trials and registries for transcatheter aortic valve implantation, and the introduction of less invasive and novel approaches of conventional aortic valve replacement surgery. Surgery for mitral valve disease is also considered, with particular reference to surgery for asymptomatic degenerative mitral regurgitation.
\end{abstract}

\section{Introduction}

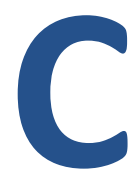

ardiac surgery remains an important treatment option for many patients with coronary artery disease, valvular heart disease and heart failure. Coronary artery remains the commonest operation undertaken in most centres, but its proportion is decreasing in the UK. ${ }^{1}$ More patients are undergoing mitral and aortic valve procedures, both by conventional and novel approaches including smaller incisions for conventional surgery and insertion of new prostheses using catheter-based devices. This article will summarise publications from recent years that are having an impact on the practice of cardiac surgery.

\section{Coronary Artery Surgery}

There are marked changes in patients coming to coronary artery surgery over time that have been shown clearly from the analyses of large series from the USA and UK. A report from the Society for Thoracic Surgeons (STS) database has described the increasing risk profile of patients coming to surgery with fewer smokers, more patients with diabetes and more use of the left internal mammary artery (LIMA) as a bypass conduit. Overall, there has been a significant decline in postoperative mortality and morbidity. ${ }^{2}$ Similar trends have been reported in the UK from the national adult cardiac surgery database, where there has been a greater than $50 \%$ reduction in risk adjusted mortality since 2000 , again with increasing risk profiles, and more use of the internal mammary artery..$^{13}$ However, despitesomeevidence for their efficacy, off-pump surgery and multiple arterial grafts have not become widespread (see below). ${ }^{1}$

\section{Coronary Artery Surgery Or Pci For Angina}

The major contemporary randomised clinical trial to inform decision making in patients with multi-vessel coronary artery disease is the Synergy between $\mathrm{PCl}$ with Taxus and Cardiac Surgery (SYNTAX) trial. The study randomised 1800 patients with previously treated three vessel or left main coronary artery disease or both in 85 sites in 17 countries across Europe and the USA. The 1-year results were published in 2009, showing that the percutaneous coronary intervention $(\mathrm{PCl})$ group had higher rates of the combined end point of major adverse cardiac or cerebrovascular events and failed to achieve the predefined end point of non-inferiority. ${ }^{4}$ This difference was driven by a high rate of repeat revascularisation in the $\mathrm{PCl}$ group (13.5\% PCl, 5.9\% coronary artery bypass grafting (CABG)). The 1-year rates of death or myocardial infarction (MI) were not different between the groups. These differences persist over longer follow-up with 3-year MACCE rates (death stroke, $\mathrm{MI}$ or repeat revascularisation) being higher in the $\mathrm{PCl}$ group (28\%) than the CABG group (20\%), again driven mainly by repeat revascularisation, but there was no difference in the primary safety end point or the incidence of stroke. On subgroup analysis, there was no difference in major adverse events in the patients with left main stem (LMS) stenosis, but outcomes were worse following $\mathrm{PCl}$ in the three vessel subgroup. ${ }^{5}$ Analysis of outcomes based on procedural risk from the syntax score has shown at 4 years that the curves are diverging overall, but with no difference in the low risk patients (http:// www.syntaxscore.com).

In line with the data from SYNTAX, a large registrybased study from the USA linked the ACCF National Cardiovascular registry and the STS adult cardiac surgery database to the Medicare and Medicaid registries and 
used propensity scoring to match patients who were 65 years or older undergoing $\mathrm{PCl}$ and $\mathrm{CABG}$. Four years after intervention there was a mortality advantage in the CABG group, which persisted in the important subgroups. ${ }^{6}$

While the late outcomes of most higher risk patients with multi-vessel coronary artery disease seem to be better with $C A B G$, in both randomised and registry-based studies, the outcome following intervention for LMS stenosis is not so clear cut, certainly during early follow-up. In a meta-analysis of patients with unprotected LMS stenosis analysing 2905 patients from eight clinical studies, there was no significant difference between the two groups with respect to mortality or a composite end point of death, MI or stroke at 1 year.7 Another meta-analysis of 3773 patients looking out to 3 years gave similar findings. 8 Analysis of the left main subgroup of the SYNTAX study also showed no difference up to 3 years. 59 More recently, the Premier of Randomised Comparison of Bypass Surgery Versus Angioplasty using SirolimusEluting Stent in Patients with Coronary Artery Disease trial has reported results of 300 patients in each arm to 2 years, and showed $\mathrm{PCl}$ to be non-inferior, but the authors accept that the non-inferiority margin was wide, leaving open the need for further studies.10 Similar findings have also been detected in a smaller study.11 To understand better the safety and efficacy of the place of PCI for LMS stenosis, the Evaluation of Xience Prime versus Coronary Artery Bypass Surgery for Effectiveness of Left Main Revascularisation trial is ongoing in patients with LMS disease and syntax scores of \#32.12 13

\section{ESC/EACTS Revascularisation guidelines}

The European Society for Cardiology and European Association of Cardiothoracic Surgery published guidelines for revascularisation in 2010 that were developed by a balanced writing team of interventional cardiologists, non-interventional cardiologists and surgeons. The guidelines recommend decision making through an appropriately configured 'heart team' and suggest that surgery is the better option for revascularisation for the majority of anatomical forms of coronary artery disease. ${ }^{14}$ Data published since the guidelines were released, including later analyses of the SYNTAX trial, have further reinforced the evidence on which the guidelines were based. Potential implications of these recommendations have been reported, ${ }^{15}{ }^{16}$ but detailed analyses of any changes in practice are not yet available.

\section{Is off Pump Coronary Artery Surgery Safe?}

Controversy remains surrounding the relative benefits of undertaking coronary artery surgery with or without the cardiopulmonary bypass machine. ${ }^{1718} \mathrm{In}$ the UK, around $20 \%$ of cases are undertaken off pump but there are conflicting data about safety and longer-term outcomes. $^{1}$

Concern was raised from the ROOBY trial in which 2203 patients undergoing CABG were randomised to surgery on or off pump. There was no significant difference in 30-day mortality, but there were a higher proportion of patients receiving fewer grafts than planned in the off- pump group. Of concern, there was a significantly worse 1-year composite end point of death, repeat revascularisation or non-fatal $\mathrm{Ml}$ and poorer graft patency in the off-pump group. ${ }^{19}$ Critics of the study have commented that the trial enrolled low risk, male patients who would be the least likely to benefit from avoiding cardiopulmonary bypass, the surgeons were inexperienced and there was a high (12\%) rate of intraoperative conversion to bypass surgery. ${ }^{20}$ Furthermore, endoscopic vein harvesting was associated with worse outcomes at 1 year in the study (see further below). ${ }^{21}$ In addition, Moller et al have reported randomised trial data on 341 high risk (EuroSCORE >5) patients with three vessel disease undergoing surgery on or off pump in the Best Bypass Surgery trial. There was no significant difference in primary outcome of adverse cardiac and cerebrovascular events during a median follow-up of 3.7 years, although all cause mortality was higher in the off-pump group. ${ }^{22}$

More reassuring data have recently been published from the MASS 3 trial with 5-year follow-up from a single centre with no difference in a composite end point of death, MI or further revascularisation between the groups and from the CORONARY study, which randomised 4752 patients to on or off pump and showed no significant difference in 30-day mortality or the incidence of $\mathrm{MI}$, stroke and renal failure. ${ }^{2324}$ Later outcomes data from this study are awaited with interest.

There has also been a meta-analysis of 35 propensity score studies on 123137 patients undergoing on or off pump surgery. This suggested that off-pump surgery was superior for short-term mortality and other outcomes. ${ }^{25}$ In a single centre study of 14766 patients reported by Puskas et al there was no difference in operative mortality in the lowest risk quartile but increasing benefit for higher risk patients, which supports the argument used by critics of the findings of the ROOBY study. ${ }^{26}$ Similar findings have been reported on 349 survivors of two randomised studies comparing on and of pump surgery in which 199 patients had graft patency assessed, and in 299 patients health-related quality of life, with no difference seen between the groups at $6 \mathrm{e} 8$ years. ${ }^{27}$

While the benefits or otherwise of off-pump surgery are not yet clearly defined, there remains interest in optimising outcomes from on-pump surgery by refining bypass techniques. For example, a recent trial has drawn attention to how the brain might be protected by using a minimal extracorporeal circulation. ${ }^{28}$ In this randomised comparison of minimal versus conventional extracorporeal circulation, the minimal circuit was associated with improved cerebral perfusion during cardiopulmonary bypass and improved neurocognitive performance on direct testing at discharge, with evidence of sustained effects at 3 and 14 months. The data suggest that some of the advantages proposed by offpump enthusiasts, particularly cerebral protection, might be achieved by modifying on-pump strategies.

\section{Is endoscopic vein harvesting safe?}

In line with other moves towards less invasive surgery, there has been a significant move towards harvest- 
ing the long saphenous vein through minimally invasive, including endoscopic, approaches but there remains some concern over safety. As described previously, a subgroup analysis of the ROOBY trial suggested that endoscopic vein harvesting was associated with worse outcomes. ${ }^{21} \mathrm{~A}$ secondary analysis of patients from the PREVENT IV trial at 3 years of follow-up also showed worse outcomes for patients undergoing endoscopic harvesting, but this finding has not been confirmed in other observational studies. ${ }^{29-31}$

\section{Should Bilateral Internal Mammary Artery Grafts Be Used For Coronary Artery Surgery?}

It is generally accepted that using the LIMA graft to the left anterior descending coronary artery is associated with better inhospital mortality, long-term survival and freedom from angina, and a number of observers suggest that if one mammary is good, two would be better. Despite this, $<10 \%$ of coronary artery operations in the UK receive both internal mammary arteries. ${ }^{1}$ To address this, the ART trial is a large randomised study, which has now reported 1-year data on 1554 patients receiving a single LIMA graft and 1548 receiving bilateral mammary arteries (BIMA). It has been powered to look at survival at 10 years. The 1 -year data show no mortality difference between the groups but there was a three times increase in the rate of sternal wound reconstruction in the BIMA group..$^{32}$ In view of our understanding of the timing of vein graft failure it would have been surprising to see any benefit from BIMA grafting at this stage. Further supportive evidence for the beneficial effect of BIMA has been shown from a single centre propensity matched study of 928 BIMA versus 928 LIMA and saphenous vein grafts reporting to 17 years with a survival benefit of $10 \%$ at 10 years and $18 \%$ at 15 years. ${ }^{33}$

There has been great interest in the use of the radial artery as a conduit for coronary artery bypass surgery, with enthusiasts recommending its use, either alongside both internal mammary arteries for a total arterial grafting approach or in addition to a single mammary artery, to improve long-term outcomes. However, a randomised study of 733 patients comparing radial artery grafts to saphenous veins has recently shown similar graft patency at 1 year (both $89 \%) .{ }^{34}$ Of concern, the radial artery was associated with a higher incidence of vasospasm in this study and the saphenous vein had better outcomes in diabetic patients. Further concern has been raised from a study using CT scanning to assess graft patency. ${ }^{35}$ However, there remain a numbers of reports claiming good late patency rates. ${ }^{36-38}$

Most of the studies looking at comparative outcomes of different surgical strategies have relied on late outcomes, with mortality being most important, and these data are obviously difficult to collect and they only provide useful information many years 'after the event'. To help provide useful and more timely differential data, some workers have been looking at techniques to assess preoperative risk other than clinical outcomes such as per-operative injury to the left ventricular myocardium. This is hard to quantify and was the subject of a recent study from Oxford in which 40 patients underwent cardiac MR before and after CABG with serial assessment of troponin I (Tnl). ${ }^{39} \mathrm{Tnl}$ correlated closely with the mass of new cardiac MR necrosis ( $\left.r \frac{1}{4} 0.83, p<0.001\right)$, with sensitivity and specificity values of $75 \%$ and $87 \%$, making it a robust means of diagnosing this type of MI.

Alongside analyses of ways to optimise operative surgical strategy, there is also an increasing focus on non-mortality postoperative outcomes and pathways. For example, a study published in this journal has examine the implications of postoperative anaemia in a retrospective analysis of 2553 CABG patients included in the IMAGINE trial. ${ }^{40}$ They showed that postoperative anaemia sustained for $>50$ days is associated with an increased incidence of cardiovascular events during the first 3 months. The researchers also found that ACE inhibition slowed recovery from postoperative anaemia and increased the incidence of cardiovascular events after CABG, although the mechanism and therapeutic implication of this observation is not clear. It is also become increasingly accepted that formal cardiac rehabilitation is beneficial to enhance recovery after CABG surgery, with an emphasis being placed on exercise programmes. While the best means of delivering these programmes is unclear, a Canadian study favoured a home-based strategy based on a 6-year follow-up of patients randomised to hospital versus telephone-monitored home-based exercise training. ${ }^{41}$

\section{Coronary Artery Surgery For Heart Failure?}

The STICH trial has showed that there is no difference in survival between patients with heart failure and poor left ventricular function, randomised to either medical therapy or medical therapy plus CABG. In a subset of this study in which myocardial viability was assessed, the presence of viable myocardium was associated with better survival overall, but this was not significant after adjusting for other baseline variables. ${ }^{42}$ ${ }^{43}$ Taken at face value these are profound findings for the practice of coronary artery surgery and are at odds with many physicians and surgeons preconceptions, but some observers have questioned whether the findings of the trial are valid because of difficulties in trial recruitment leading to changes in trial design after instigation alongside a crossover rate of $17 \%$ to $C A B G$, therefore underestimating the benefits of surgery and suggesting that CABG should still be considered if CAD is severe and viable myocardium is seen. ${ }^{44}$ For example, a recent propensity matched study of CABG versus medical therapy in these patients (designed to mimic the STICH trial inclusion) showed a clear survival advantage of CABG at 10 years. ${ }^{45}$

\section{Aortic Valve Surgery}

The practice of aortic valve surgery is changing. In the USA, an analysis of 108687 isolated aortic valve replacement (AVR) patients from 1997 to 2006 was reported in $2009 .{ }^{46}$ Morbidity and mortality have fallen despite gradual increases in patient age and overall risk profile, alongside an increase in biological valve use. 
Similar trends have been seen in the UK with a report of 41227 patients between 2004 and 2009 with an overall inhospital mortality of $4.1 \%$. The annual number increased by $20 \%$, with significant increases in the mean age of patients with aortic stenosis, octogenarians, the proportion of high-risk patients and again those receiving biological valves (which is almost certainly influenced by surgeons' views of better longevity of modern biological valves and the promise of a transcatheter valve solution for subsequent valve failure).$^{47}$ Over this time, inhospital mortality decreased from $4.4 \%$ to $3.7 \% .{ }^{48}$ While transcatheter valve insertion (TAVI) (see below) is having an impact on valve surgery, in contract to just eroding the numbers of conventional valve operations, it has been reported that starting a TAVI service may increase overall aortic valve interventions, including those for conventional surgery. ${ }^{49}$

There remains some controversy about the timing of surgery in asymptomatic aortic stenosis (see parallels with mitral valve repair below). Some work is being produced suggesting benefits from earlier intervention but other observers have published data suggesting benefits and safety of the watchful waiting approach. ${ }^{50-53}$

\section{Transcatheter Valve Insertion}

The major change in the treatment of patients with aortic stenosis in recent years has been the advent of TAVI, which has now been shown to be a good option for the treatment of some patients with aortic stenosis. The Partner study Cohort A trial of 358 patients who were not considered suitable for conventional AVR showed that TAVI decreased the rate of mortality at 1 year (from $51 \%$ to $31 \%$ ) and reduced cardiac symptoms compared with conventional treatment. ${ }^{54}$ The 2-year results have also been reported showing persistent survival advantage, but a high rate of stroke in the TAVI group, due to more ischaemic strokes in the first 30 days after the procedure and more haemorrhagic events thereafter. The rate of rehospitalisation was 35\% in the TAVI group and $72 \%$ in the conventional group. Quality of life studies on these patients using the Kansas City Cardiomyopathy Questionnaire and the SF-12 showed significant benefits in the TAVI group going out to 1 year. ${ }^{55} \mathrm{An}$ economic analysis of these data demonstrated an incremental cost per life-year gained that was well within the acceptable range. ${ }^{56}$

TAVI has also been shown to be comparable with conventional aortic valve surgery. In the Partner study Cohort B, 699 patients with severe aortic stenosis who were deemed to be high risk were randomised to TAVI or conventional surgery. ${ }^{57}$ There was no significant difference in mortality rates at 30 days (3.4\% TAVI and $6.5 \%$ conventional surgery) or 1 year (24.2\% TAVI, $26.8 \%$ conventional surgery). Two-year data have also been reported, again showing no difference in mortality rates. ${ }^{58}$ Procedural complication rates were different between the groups, with major vascular complications being more common in the TAVI patients and bleeding and new onset atrial fibrillation (AF) more common in conventional surgery. A number of large registry studies have also confirmed acceptable procedural and longerterm outcomes. ${ }^{59-63}$

Transcatheter aortic valves are now being inserted in increasing numbers through the femoral artery, transapically directly via the left ventricle and through the aortic approach. ${ }^{64-66}$ In response to potential benefits from less invasive approaches, there has also been increasing interest in conducting 'conventional' surgery through a variety of smaller incisions including ministernotomy, para-sternotomy, transverse sternotomy and right anterior thoracotomy. Various studies including single centre experiences and meta-analyses have shown that it can be applied safely in expert centres. ${ }^{67}$ ${ }^{68}$ Alongside less invasive approaches, to minimise insertion times and allow easier valve implantation through small incisions, various novel aortic valves are being developed and tested which have 'sutureless' implantation techniques. ${ }^{69} 70$

A final word on aortic valve surgery and TAVI is that there are now consensus statements produced about the practice of TAVI and to understand better how to achieve optimal outcomes from conventional AVR, health service research studies have shown that outcomes of surgery are better for higher risk patients under high volume surgeons, which lay down a challenge for configuration of surgical services for these patients. ${ }^{7172}$

\section{Mitral Valve Surgery}

The major advances in understanding of mitral valve surgery in recent years are related to mitral valve repair. It is now well accepted that repair is a better option than replacement for most patients with degenerative mitral valve disease, and that inhospital and later mortality outcomes are dependent on the degree of symptoms and left ventricular dysfunction at the time of surgery. Evidence from the UK suggests that many patients are still being referred late in the disease process with $47 \%$ of patients having NYHA class 3 or 4 symptoms and $31 \%$ of people displaying left ventricular (LV) ejection fractions of $<50 \%$ at the time of surgery. ${ }^{1}$

Surgical treatment for mitral valve disease is changing over time, and a report on 58370 patients with isolated mitral regurgitation from the STS database in the 8 years to December 2007 showed progressive adoption of mitral repair rather than replacement from $51 \%$ to $69 \%$. There was also a decrease in the use of mechanical rather than biological valves over that time from $68 \%$ to $37 \%$ (and there are similar data from the UK). ${ }^{173}$ This, of course, indicates that one in three patients with severe MR undergo a valve replacement, and this remains a concern from the perspective of health service delivery. $^{74}$

The major controversy around patients with severe $\mathrm{MR}$ is around the timing of surgery. There are no randomised trial data to support early surgery or 'watchful waiting' and so the evidence is derived from observation studies. In 2005, Enriquez-Sarano and colleagues from the Mayo Clinic reported an observational study on 456 patients with symptomatic organic mitral regurgitation, showing that patients with an effective regur- 
gitant orifice area of $>40 \mathrm{~mm}^{2}$ had a survival at 5 years that was lower than expected. ${ }^{75} \mathrm{On}$ this basis, they recommended mitral valve repair for patients with genuinely severe mitral regurgitation, purely on the basis of symptoms, irrespective of left ventricular size or function. Similar findings have been reported from Korea on 447 consecutive asymptomatic patients undergoing early surgery or conventional treatment strategy with early surgery associated with improved long-term event rates by decreasing cardiac mortality and congestive heart failure hospitalisation. ${ }^{76} \mathrm{~A}$ further observational study of 192 patients followed up for 8.5 years, divided into an early surgery and a conservative group, also showed better outcomes in the conservative group. ${ }^{77}$

Conversely, Rosenhek et al have reported outcomes on 132 patients and only intervened at the time of onset of symptoms, left ventricular impairment or significant LV dilatation according to the accepted guidelines of the time of onset of symptoms, left ventricular impairment or significant LV dilatation. ${ }^{7879}$ Overall, late outcomes were excellent, and only a third of patients required surgery during the follow-up period of 5 years, but it is obviously important that if this strategy is followed, followup must be robust and comprehensive.

Guidance from the American College of Cardiology/ American Heart Association from 2006 suggests that early surgery should be considered for asymptomatic patients at low procedural risk in 'experienced centres' as long as the likelihood of successful repair is $>90 \%{ }^{80}$ An attempt has been made from a UK consensus study to describe the criteria associated with an experienced centre. ${ }^{81}$ However, if one comes from an surgical epidemiology approach there must be some concern about an overall early surgery strategy for these patients. ${ }^{74}$ In a report of 13614 patients with mitral regurgitation undergoing surgery from the STS database there was marked variation in overall volumes per year, and higher volume centres showed higher rates of valve repair and lower risk adjusted mortality. ${ }^{82}$ Again from the STS database in an analysis of 28507 patients undergoing isolated mitral valve surgery with or without tricuspid valve or concomitant AF surgery under 1088 surgeons, the mean rate of repair by surgeon was only $41 \%$. The median annual number of operation was 5 (1-166) and increasing surgeon volume was independently associated with increased probability of repair. ${ }^{83}$ The consensusbased opinion study from the UK has suggested that hospitals should be undertaking more than 50 mitral repair operations each year to get optimal outcomes, and individual surgeons should be doing more than 25 . It seems that many hospitals and surgeons fall short of this. Offering an early surgical strategy in the absence of assurance about high repair rates and excellent durability of repair procedures may not be in the patients' best interests.

There have been some developments in the techniques of mitral valve repair with a move towards more use of artificial chordae tendinae and preservation of leaflet tissue rather than resection and increasing use of less invasive techniques. ${ }^{84-89}$ While there are a growing number of reports suggesting the safety of minimally invasive approaches, there is significant anecdotal reporting of the concern about these techniques and their safety.

There are also developments in catheter-based treatments of mitral regurgitation, and the Endovascular valve edge to edge repair (EVEREST 2) trial has reported the outcomes of 78 patients at high risk from conventional surgery having an 'edge to edge' treatment with the 'MitralClip' showing a procedural mortality of $7.7 \%$ with a reduction in MR in most patients with an improvement in clinical symptoms in three-fourths of the patients. ${ }^{90}$

\section{RISK MODELLING}

The assessment of operative risk in cardiac surgery is important to guide decision making (eg, conventional surgery or TAVI for patients with aortic stenosis), support informed consent and for governance and public reporting of hospital and surgeon mortality rates. The STS scores were published in 2009 after analysing data from the STS database, with models published for coronary artery surgery, valve surgery and combined coronary and valve surgery. These model a standard set of outcomes for all procedures including mortality, stroke, reoperation, renal failure, deep sternal wound infection, prolonged ventilation, composite major morbidity, prolonged length of stay and short length of stay. ${ }^{91-94}$

More recently, it has been accepted that the EuroSCORE is no longer suitable for contemporary practice and the EuroSCORE 2 has been published. ${ }^{95}{ }^{96}$ Unlike the STS models, which are procedure specific, the EuroSCORE 2 is a generic model covering all cardiac surgery, which has some potential strengths and weaknesses. It was derived from a patient population of $22381 \mathrm{con}-$ secutive patients undergoing major cardiac surgery in 154 hospitals in 43 countries over a 12 -week period (May 2010 to July 2010). The fields required to derive the score have been updated from the previous model and include creatinine clearance, modifications to the categorisation of $L V$ ejection fraction and introduction of a limited mobility field. ${ }^{9697}$ The 'weight of intervention' is also dealt with differently from the original EurOSCORE model. The developers report good discrimination and calibration and it is likely this model will be widely adopted, but it will require robust external validation. There remains debate about the derivation and use of this type of model. ${ }^{98}$

Contributors BB wrote the manuscript.

Competing interests None.

Provenance and peer review Commissioned; internally peer reviewed. 


\section{References}

1. Bridgewater $B$, Kinsman $R$, Walton $P$, et al. Demonstrating Quality; The Sixth National Annual Cardiac Database Report. Henleyon Thames: Dendrite Clinical Systems Ltd, 2009.

2. ElBardissi AW, Aranki SF, Sheng S, et al. Trends in isolated coronary artery bypass grafting: an analysis of the Society of Thoracic Surgeons adult cardiac surgery database. J Thorac Cardiovasc Surg 2012;143:273-81.

3. Bridgewater B. Cardiac registers: the adult cardiac surgery register. Heart 2010;96:1441-3.

4. Serruys PW, Morice MC, Kappetein AP, et al. Percutaneous coronary intervention versus coronary-artery bypass grafting for severe coronary artery disease. N Engl J Med 2009;360:961-72.

5. Kappetein AP, Feldman TE, Mack MJ, et al. Comparison of coronary bypass surgery with drug-eluting stenting for the treatment of left main and/or three-vessel disease: 3-year follow-up of the SYNTAX trial. Eur Heart J 2011;32:2125-34.

6. Weintraub WS, Grau-Sepulveda MV, Weiss JM, et al. Comparative effectiveness of revascularization strategies. N Engl J Med 2012;366:1467-76.

7. Lee MS, Yang T, Dhoot J, et al. Meta-analysis of clinical studies comparing coronary artery bypass grafting with percutaneous coronary intervention and drug-eluting stents in patients with unprotected left main coronary artery narrowings. Am J Cardiol 2010;105:1070-5.

8. Naik H, White AJ, Chakravarty T, et al. A meta-analysis of 3,773 patients treated with percutaneous coronary intervention or surgery for unprotected left main coronary artery stenosis. JACC Cardiovasc Interv 2009;2:739-47.

9. Morice MC, Serruys PW, Kappetein AP, et al. Outcomes in patients with de novo left main disease treated with either percutaneous coronary intervention using paclitaxel-eluting stents or coronary artery bypass graft treatment in the Synergy Between Percutaneous Coronary Intervention with TAXUS and Cardiac Surgery (SYNTAX) trial. Circulation 2010;121:2645-53.

10. Park SJ, Kim YH, Park DW, et al. Randomized trial of stents versus bypass surgery for left main coronary artery disease. $\mathrm{N}$ Engl J Med 2011;364:1718-27.

11. Boudriot $\mathrm{E}$, Thiele $\mathrm{H}$, Walther $\mathrm{T}$, et al. Randomized comparison of percutaneous coronary intervention with sirolimus-eluting stents versus coronary artery bypass grafting in unprotected left main stem stenosis. J Am Coll Cardiol 2011;57:538-45.

12. Capodanno D, Tamburino C. Unraveling the EXCEL: promises and challenges of the next trial of left main percutaneous coronary intervention. Int J Cardiol 2012;156:1-3.

13. Capodanno D, Caggegi A, Capranzano $P$, et al. Validating the EXCEL hypothesis: a propensity score matched 3-year comparison of percutaneous coronary intervention versus coronary artery bypass graft in left main patients with SYNTAX score $</ 1 / 432$ Catheter Cardiovasc Interv 2011;77:936-43.

14. Wijns W, Kolh P, Danchin N, et al. Guidelines on myocardial revascularization. Eur Heart J 2010;31:2501-55

15. Ribichini F, Taggart D. Implications of new ESC/EACTS guidelines on myocardial revascularisation for patients with multi-vessel coronary artery disease. Eur J Cardiothorac Surg 2011;39:619-22.

16. Taggart DP, Boyle R, de Belder MA, et al. The 2010 ESC/EACTS gu idelines on myocardial revascularisation. Heart 2011;97:445-6.

17. Falk V, Taggart DP. NICE guidance for off-pump CABG: turn off the pump. Heart 2011;97:1731-3.

18. Pepper JR. NICE guidance for off-pump CABG: keep the pump primed. Heart 2011;97:1728-30.

19. Shroyer AL, Grover FL, Hattler B, et al. On-pump versus off-pump coronary-artery bypass surgery. N Engl J Med 2009;361:1827-37.

20. Puskas JD, Mack MJ, Smith CR. On-pump versus off-pump CABG. N Engl J Med 2010;362:851; author reply 53-4.

21. Zenati MA, Shroyer AL, Collins JF, et al. Impact of endoscopic versus open saphenous vein harvest technique on late coronary artery bypass grafting patient outcomes in the ROOBY (Randomized On/Off Bypass) Trial. J Thorac Cardiovasc Surg 2011;141:338-44.

22. Moller $\mathrm{CH}$, Perko MJ, Lund JT, et al. Three-year follow-up in a subset of high-risk patients randomly assigned to off-pump ver- sus on-pump coronary artery bypass surgery: the Best Bypass Surgery trial. Heart 2011;97:907-13.

23. Hueb W, Lopes NH, Pereira AC, et al. Five-year follow-up of a randomized comparison between off-pump and on-pump stable multivessel coronary artery bypass grafting. The MASS III Trial. Circulation 2010;122(Suppl 11):S48-52.

24. Lamy A, Devereaux PJ, Prabhakaran D, et al. Off-pump or onpump coronary-artery bypass grafting at 30 days. N Engl J Med 2012;366(16):1489-97.

25. Kuss O, von Salviati B, Borgermann J. Off-pump versus on-pump coronary artery bypass grafting: a systematic review and metaanalysis of propensity score analyses. J Thorac Cardiovasc Surg 2010;140:829-35, 35 e1-13.

26. Puskas JD, Thourani VH, Kilgo $P$, et al. Off-pump coronary artery bypass disproportionately benefits high-risk patients. Ann Thorac Surg 2009;88:1142-7.

27. Angelini GD, Culliford L, Smith DK, et al. Effects of on-and offpump coronary artery surgery on graft patency, survival, and health-related quality of life: long-term follow-up of 2 randomized controlled trials. J Thorac Cardiovasc Surg 2009;137:295-303.

28. Anastasiadis K, Argiriadou H, Kosmidis MH, et al. Neurocognitive outcome after coronary artery bypass surgery using minimal versus conventional extracorporeal circulation: a randomised controlled pilot study. Heart 2011;97:1082-8.

29. Lopes RD, Hafley GE, Allen KB, et al. Endoscopic versus open vein-graft harvesting in coronary-artery bypass surgery. $\mathrm{N}$ Engl J Med 2009;361:235-44.

30. Grant SW, Grayson AD, Zacharias J, et al. What is the impact of endoscopic vein harvesting on clinical outcomes following coronary artery bypass graft surgery? Heart 2012;98:604.

31. Ouzounian M, Hassan A, Buth KJ, et al. Impact of endoscopic versus open saphenous vein harvest techniques on outcomes after coronary artery bypass grafting. Ann Thorac Surg 2010;89:403-8.

32. Taggart DP, Altman DG, Gray AM, et al. Randomized trial to compare bilateral vs. single internal mammary coronary artery bypaSs grafting: 1-year results of the Arterial Revascularisation Trial (ART). Eur Heart J 2010;31:2470-81.

33. Grau JB, Ferrari G, Mak AW, et al. Propensity matched analysis of bilateral internal mammary artery versus single left internal mammary artery grafting at 17-year follow-up: validation of a contemporary surgical experience. Eur J Cardiothorac Surg 2012;41:770-5; discussion 76.

34. Goldman S, Sethi GK, Holman W, et al. Radial artery grafts vs saphenous vein grafts in coronary artery bypass surgery: a randomized trial. JAMA 2011;305:167-74.

35. Levisman JM, Budoff MJ, Karlsberg RP. Long-term coronary artery graft patency as evaluated by 64-slice coronary computed tomographic angiography. Coron Artery Dis 2011;22:521-5.

36. Achouh P, Boutekadjirt R, Toledano D, et al. Long-term (5-to 20-year) patency of the radial artery for coronary bypass grafting. J Thorac Cardiovasc Surg 2010;140:73-9, 79 e1-2.

37. Hayward PA, Buxton BF. The Radial Artery Patency and Clinical Outcomes trial: design, intermediate term results and future direction. Heart Lung Circ 2011;20:187-92.

38. Hayward PA, Gordon IR, Hare DL, et al. Comparable patencies of the radial artery and right internal thoracic artery or saphenous vein beyond 5 years: results from the Radial Artery Patency and Clinical Outcomes trial. J Thorac Cardiovasc Surg 2010;139:60-5; discussion 65-7.

39. Pegg TJ, Maunsell Z, Karamitsos TD, et al. Utility of cardiac biomarkers for the diagnosis of type $\mathrm{V}$ myocardial infarction after coronary artery bypass grafting: insights from serial cardiac MRI. Heart 2011;97:810-16.

40. Westenbrink BD, Kleijn L, de Boer RA, et al. Sustained postoperative anaemia is associated with an impaired outcome after coronary artery bypass graft surgery: insights from the IMAGINE trial. Heart 2011;97:1590-6.

41. Smith KM, McKelvie RS, Thorpe KE, et al. Six-year follow-up of a randomised controlled trial examining hospital versus home-based exercise training after coronary artery bypass graft surgery. Heart 2011;97:1169-74.

42. Velazquez EJ, Lee KL, Deja MA, et al. Coronary-artery bypass surgery in patients with left ventricular dysfunction. N Engl J Med 2011;364:1607-16. 
43. Bonow RO, Maurer G, Lee KL, et al. Myocardial viability and survival in ischemic left ventricular dysfunction. N Engl J Med 2011;364:1617-25.

44. Mack MJ. Coronary artery disease: how should the STICH trial results affect clinical practice? Nat Rev Cardiol 2011;8:427-8.

45. Velazquez EJ, Williams JB, Yow E, et al. Long-term survival of patients with ischemic cardiomyopathy treated by coronary artery bypass grafting versus medical therapy. Ann Thorac Surg 2012;93:523-30.

46. Brown JM, O'Brien SM, Wu C, et al. Isolated aortic valve replacement in North America comprising 108,687 patients in 10 years: changes in risks, valve types, and outcomes in the Society of Thoracic Surgeons National Database. J Thorac Cardiovasc Surg 2009;137:82-90.

47. Cockburn J, Trivedi U, Hildick-Smith D. Transaortic transcatheter aortic valve implantation within a previous bioprosthetic aortic valve replacement. Catheter Cardiovasc Interv 2011;78:479-84.

48. Dunning J, Gao H, Chambers J, et al. Aortic valve surgery: marked increases in volume and significant decreases in mechanical valve usedan analysis of 41,227 patients over 5 years from the Society for Cardiothoracic Surgery in Great Britain and Ireland National database. J Thorac Cardiovasc Surg 2011;142:776-82 e3.

49. Grant SW, Devbhandari MP, Grayson AD, et al. What is the impact of providing a transcatheter aortic valve implantation service on conventional aortic valve surgical activity: patient risk factors and outcomes in the first 2 years. Heart 2010;96:1633-7.

50. Kang DH, Park SJ, Rim JH, et al. Early surgery versus conventional treatment in asymptomatic very severe aortic stenosis. Circulation 2010;121:1502-9.

51. Brown ML, Pellikka PA, Schaff HV, et al. The benefits of early valve replacement in asymptomatic patients with severe aortic stenosis. J Thorac Cardiovasc Surg 2008;135:308-15.

52. Le Tourneau T, Pellikka PA, Brown ML, et al. Clinical outcome of asymptomatic severe aortic stenosis with medical and surgical management: importance of STS score at diagnosis. Ann Thorac Surg 2010;90:1876-83.

53. Avakian SD, Grinberg M, Ramires JA, et al. Outcome of adults with asymptomatic severe aortic stenosis. Int J Cardiol 2008;123:322-7.

54. Leon MB, Smith CR, Mack M, et al. Transcatheter aortic-valve implantation for aortic stenosis in patients who cannot undergo surgery. N Engl J Med 2010;363:1597-607.

55. Reynolds MR, Magnuson EA, Lei Y, et al. Health-related quality of life after transcatheter aortic valve replacement in inoperable patients with severe aortic stenosis. Circulation 2011;124:1964-72.

56. Reynolds MR, Magnuson EA, Wang K, et al. Cost-effectiveness of transcatheter aortic valve replacement compared with standard care among inoperable patients with severe aortic stenosis: results from the placement of aortic transcatheter valves (PARTNER) trial (Cohort B). Circulation 2012;125:1102-9.

57. Smith CR, Leon MB, Mack MJ, et al. Transcatheter versus surgical aortic-valve replacement in high-risk patients. N Engl J Med 2011:364:2187-98.

58. Kodali SK, Williams MR, Smith CR, et al. Two-year outcomes after transcatheter or surgical aortic-valve replacement. N Engl J Med 2012;366:1686-95.

59. Moat NE, Ludman P, de Belder MA, et al. Long-term outcomes after transcatheter aortic valve implantation in high-risk patients with severe aortic stenosis: the U.K. TAVI (United Kingdom Transcatheter Aortic Valve Implantation) Registry. J Am Coll Cardiol 2011;58:2130-8.

60. Zahn R, Gerckens U, Grube E, et al. Transcatheter aortic valve implantation: first results from a multi-centre real-world registry. Eur Heart J 2011;32:198-204.

61. Lefevre T, Kappetein AP, Wolner E, et al. One year follow-up of the multi-centre European PARTNER transcatheter heart valve study. Eur Heart J 2011;32:148-57.

62. Gilard $M$, Eltchaninoff $H$, lung $B$, et al. Registry of transcatheter aortic-valve implantation in high-risk patients. N Engl J Med 2012;366:1705-15.

63. Ussia GP, Barbanti M, Colombo A, et al. Impact of coronary artery disease in elderly patients undergoing transcatheter aortic valve implantation: insight from the Italian CoreValve Registry.
Int J Cardiol. Published Online First: 27 March 2012 PMID: 22459391.

64. Eltchaninoff H, Durand E, Borz B, et al. Prospective analysis of 30-day safety and performance of transfemoral transcatheter aortic valve implantation with Edwards SAPIEN XT versus SAPIEN prostheses. Arch Cardiovasc Dis 2012;105:132-40.

65. Bapat V, Khawaja MZ, Attia R, et al. Transaortic Transcatheter Aortic valve implantation using Edwards Sapien valve: a novel approach. Catheter Cardiovasc Interv 2012;79:733-40.

66. Litzler PY, Borz B, Smail H, et al. Transapical aortic valve implantation in Rouen: four years' experience with the Edwards transcatheter prosthesis. Arch Cardiovasc Dis 2012;105:141-5.

67. Murtuza B, Pepper JR, Stanbridge RD, et al. Minimal access aortic valve replacement: is it worth it? Ann Thorac Surg 2008;85:1121-31.

68. Brown ML, McKellar SH, Sundt TM, et al. Ministernotomy versus conventional sternotomy for aortic valve replacement: a systematic review and meta-analysis. J Thorac Cardiovasc Surg 2009;137:670-9 e5.

69. Zannis K, Folliguet T, Laborde F. New sutureless aortic valve prosthesis: another tool in less invasive aortic valve replacement. Curr Opin Cardiol 2012;27:125-9.

70. Folliguet TA, Laborde F, Zannis K, et al. Sutureless perceval aortic valve replacement: results of two European centers. Ann Thorac Surg 2012;93:1483-8.

71. Holmes DR Jr, Mack MJ, Kaul S, et al. 2012 ACCF/AATS/SCAI/STS expert consensus document on transcatheter aortic valve replacement. J Am Coll Cardiol 2012;59:1200-54.

72. Dewey TM, Herbert MA, Ryan WH, et al. Influence of surgeon volume on outcomes with aortic valve replacement. Ann Thorac Surg 2012;93:1107-12; discussion 12-3.

73. Gammie JS, Sheng S, Griffith BP, et al. Trends in mitral valve surgery in the United States: results from the Society of thoracic surgeons adult cardiac surgery database. Ann Thorac Surg 2009;87:1431-7; discussion 37-9.

74. Anyanwu AC, Bridgewater B, Adams DH. The lottery of mitral valve repair surgery. Heart 2010;96:1964-7.

75. Enriquez-Sarano M, Avierinos JF, Messika-Zeitoun D, et al. Quantitative determinants of the outcome of asymptomatic mitral regurgitation. N Engl J Med 2005;352:875-83.

76. Kang DH, Kim JH, Rim JH, et al. Comparison of early surgery versus conventional treatment in asymptomatic severe mitral regurgitation. Circulation 2009;119:797-804.

77. Montant $P$, Chenot $F$, Robert $A$, et al. Long-term survival in asymptomatic patients with severe degenerative mitral regurgitation: a propensity score-based comparison between an early surgical strategy and a conservative treatment approach. J Thorac Cardiovasc Surg 2009;138:1339-48.

78. Rosenhek R, Rader F, Klaar U, et al. Outcome of watchful waiting in asymptomatic severe mitral regurgitation. Circulation 2006;113:2238-44.

79. Rosenhek R. Watchful waiting for severe mitral regurgitation. Semin Thorac Cardiovasc Surg 2011;23:203-8.

80. Bonow RO, Carabello BA, Kanu C, et al. ACC/AHA 2006 guidelines for the management of patients with valvular heart disease: a report of the American College of Cardiology/American heart Association Task Force on practice guidelines (writing committee to revise the 1998 guidelines for the management of patients with valvular heart disease): developed in collaboration with the Society of cardiovascular Anesthesiologists: endorsed by the Society for cardiovascular angiography and interventions and the Society of thoracic surgeons. Circulation 2006;114:e84-231.

81. Bridgewater B, Hooper T, Munsch C, et al. Mitral repair best practice: proposed standards. Heart 2006;92:939-44.

82. Bolling SF, Li S, O'Brien SM, et al. Predictors of mitral valve repair: clinical and surgeon factors. Ann Thorac Surg 2010;90:190411; discussion 12.

83. Gammie JS, O'Brien SM, Griffith BP, et al. Influence of hospital procedural volume on care process and mortality for patients undergoing elective surgery for mitral regurgitation. Circulation 2007;115:881-7.

84. Perier $\mathrm{P}$, Hohenberger $\mathrm{W}$, Lakew $\mathrm{F}$, et al. Toward a new paradigm for the reconstruction of posterior leaflet prolapse: midterm re- 
sults of the "respect rather than resect" approach. Ann Thorac Surg 2008;86:718-25; discussion 18-25.

85. Gammie JS, Bartlett ST, Griffith BP. Small-incision mitral valve repair: safe, durable, and approaching perfection. Ann Surg 2009;250:409-15.

86. Gammie JS, Zhao Y, Peterson ED, et al. J. Maxwell Chamberlain Memorial Paper for adult cardiac surgery. Less-invasive mitra valve operations: trends and outcomes from the Society of thoracic surgeons adult cardiac surgery database. Ann Thorac Surg 2010;90:1401-8, 10 e1; discussion 08-10.

87. Modi P, Hassan A, Chitwood WR Jr. Minimally invasive mitral valve surgery: a systematic review and meta-analysis. Eur J Cardiothorac Surg 2008; 34:943-52.

88. Cheng DC, Martin J, Lal A, et al. Minimally invasive versus conventional open mitral valve surgery: a meta-analysis and systematic review. Innovations (Phila) 2011;6:84-103.

89. Iribarne A, Russo MJ, Easterwood R, et al. Minimally invasive versus sternotomy approach for mitral valve surgery: a propensity analysis. Ann Thorac Surg 2010;90:1471-7; discussion 77-8.

90. Whitlow PL, Feldman T, Pedersen WR, et al. Acute and 12-month results with catheter-based mitral valve leaflet repair: the EVEREST II (Endovascular Valve Edgeto-Edge Repair) High Risk Study. J Am Coll Cardiol 2012;59:130-9.
91. Shahian DM, Edwards FH. The Society of Thoracic Surgeons 2008 cardiac surgery risk models: introduction. Ann Thorac Surg 2009;88(Suppl 1):S1.

92. O'Brien SM, Shahian DM, Filardo G, et al. The Society of Thoracic Surgeons 2008 cardiac surgery risk models: part 2eisolated valve surgery. Ann Thorac Surg 2009;88 (1 Suppl):S23-42.

93. Shahian DM, O'Brien SM, Filardo G, et al. The Society of Thoracic Surgeons 2008 cardiac surgery risk models: part 3evalve plus coronary artery bypass grafting surgery. Ann Thorac Surg 2009;88(1 Suppl):S43-62.

94. Shahian DM, O'Brien SM, Filardo G, et al. The Society of Thoracic Surgeons 2008 cardiac surgery risk models: part 1ecoronary artery bypass grafting surgery. Ann Thorac Surg 2009;88(1 Suppl):S2-22.

95. Choong CK, Sergeant $P$, Nashef SA, et al. The EuroSCORE risk stratification system in the current era: how accurate is it and what should be done if it is inaccurate? Eur J Cardiothorac Surg 2009;35:59-61.

96. Nashef SA, Roques F, Sharples LD, et al. EuroSCORE II. Eur J Cardiothorac Surg 2012;41:734-44; discussion 44-5.

97. Miceli A, Bruno VD, Capoun R, et al. Mild renal dysfunction in patients undergoing cardiac surgery as a new risk factor for EuroSCORE. Heart 2011;97:362-5.

98. Sergeant P, Meuris B, Pettinari M. EuroSCORE II, illum qui est gravitates magni observe. Eur J Cardiothorac Surg 2012;41:729-31. 